\title{
Receipt of employment services among Veterans Health Administration users with psychiatric diagnoses
}

\author{
Kristen M. Abraham, PhD; ${ }^{1-3^{*}}$ Dara Ganoczy, MPH; ${ }^{4}$ Matheos Yosef, PhD; ${ }^{2}$ Sandra G. Resnick, PhD; ${ }^{5-6}$ \\ Kara Zivin, $\mathbf{P h D} \mathbf{D}^{2,4,7}$ \\ ${ }^{1}$ Department of Psychology, University of Detroit Mercy, Detroit, MI; ${ }^{2}$ Department of Psychiatry, University of Michi- \\ gan Medical School, Ann Arbor, MI; ${ }^{3}$ Department of Veterans Affairs (VA) Serious Mental Illness Treatment Resource \\ and Evaluation Center, Ann Arbor, MI; ${ }^{4}$ VA Center for Clinical Management Research, Ann Arbor, MI; ${ }^{5}$ Department of \\ Psychiatry, Yale University School of Medicine, New Haven, CT; ${ }^{6}$ VA New England Mental Illness Research, Educa- \\ tion, and Clinical Center, West Haven, CT; ${ }^{7}$ Department of Health Management and Policy, School of Public Health; \\ and Institute for Social Research, University of Michigan, Ann Arbor, MI
}

\begin{abstract}
This study examined the population-based reach of Veterans Health Administration (VHA) employment services to VHA patients with psychiatric diagnoses. Reach of services includes the percentage and characteristics of people who accessed services compared with those who did not. Using clinical administrative data, we identified patients with a psychiatric diagnosis among a random sample of all patients who received VHA services in 1 yr. Among VHA patients with psychiatric diagnoses, we examined their likelihood of receiving any VHA employment services and specific types of employment services, including supported employment, transitional work, incentive therapy, and vocational assistance. We identified clinical and demographic characteristics associated with receiving employment services. Results indicated that $4.2 \%$ of VHA patients with a psychiatric diagnosis received employment services. After adjusting for clinical and demographic characteristics, VHA patients with schizophrenia and bipolar disorder were more likely to receive any employment services and to receive supported employment than were patients with depression, PTSD, or other anxiety disorders. VHA patients with depression and PTSD were more likely to receive transitional work and vocational assistance than patients with schizophrenia. Future studies should examine system-level barriers to receiving employment services and identify types of employment services most appropriate for Veterans with different psychiatric diagnoses.
\end{abstract}

Key words: access, anxiety disorders, bipolar disorder employment services, depression, mental illness, psychiatric diagnosis, PTSD, schizophrenia, supported employment, transitional work, veterans, vocational rehabilitation.

\section{INTRODUCTION}

It is well known that people with severe mental illnesses, such as schizophrenia and bipolar disorder, face

\footnotetext{
Abbreviations: $\mathrm{FY}=$ fiscal year, ICD = International Classification of Diseases, IT = incentive therapy, OIF/OEF/OND = Operation Iraqi Freedom/Operation Enduring Freedom/Operation New Dawn, PTSD = posttraumatic stress disorder, SE = supported employment, TSES = Therapeutic and Supported Employment Services, TW $=$ transitional work, VA $=$ Department of Veterans Affairs, VHA = Veterans Health Administration, Voc Assist = vocational assistance.

*Address all correspondence to Kristen M. Abraham, PhD; University of Detroit Mercy, Department of Psychology, 4001 W McNichols Rd, Detroit, MI 48221-0445; 313-5780445; fax: 313-578-0507. Email: abrahakm@udmercy.edu, Kristen.abraham2@va.gov
}

http://dx.doi.org/10.1682/JRRD.2013.05.0114 
unemployment rates far higher than the general population [1-2], despite the fact that a majority of these individuals report a desire to work [3]. Although people with depressive disorders are not always classified as having a "severe" mental illness, population-based studies suggest that they, too, have lower rates of employment than people without a mood disorder [4]. Moreover, a range of psychiatric disorders is associated with days of work lost [5]. Similarly, a large representative study of workingaged (18-64 yr old) Veterans Health Administration (VHA) patients recently found that those with psychiatric diagnoses of schizophrenia, bipolar disorder, posttraumatic stress disorder (PTSD), depression, or a substance use disorder were more likely to be unemployed, disabled, or retired than patients without psychiatric diagnoses [6]. These findings are particularly striking because, on average, VHA patients are already less likely to be employed than the general population [6].

For people with psychiatric diagnoses, employment is known to be a meaningful indicator of functioning in that it allows access to a valued social role [7] and a sense of meaning and recovery [8]. Additionally, a recent analysis found that having a working-aged member of a household with severe mental illness is associated with a 3.10 increase in the odds of household poverty [9]. While the presence of a working-aged adult with severe mental illness and an unemployed head of household were each uniquely associated with increased likelihood of household poverty, the combination of having a working-aged person with severe mental illness and an unemployed head of household was associated with an even higher likelihood and greater depth of poverty [9]. Hence, employment is critical to improving the economic situation of people with severe mental illness.

\section{Veterans Health Administration Therapeutic and Supported Employment Services}

Facilitating opportunities for employment has long been considered a relevant aspect of providing mental health treatment to Veterans with psychiatric diagnoses [10]. Currently, the VHA provides vocational rehabilitative services through the Therapeutic and Supported Employment Services (TSES) program to help Veterans with psychiatric diagnoses obtain employment and experience the therapeutic effects of work. TSES includes four primary types of vocational rehabilitative services: supported employment (SE), transitional work (TW), incentive therapy (IT), and vocational assistance (Voc Assist) [11].

SE utilizes an individualized approach to working with people to help them obtain competitive employment in a job of their choosing in the community [11]. Two meta-analyses of randomized controlled trials indicate that SE helps persons with serious mental illness obtain competitive employment [12-13]; thus, it is considered the gold standard evidence-based practice for improving employment outcomes among people with serious mental illness. By definition, SE is provided in community rather than clinical settings and includes having an employment specialist provide assistance identifying and obtaining jobs that are matched to the Veteran's interests and abilities, identifying and addressing challenges to employment, and providing ongoing support while seeking employment and while employed to the extent desired by the Veteran.

TW is a program in which Veterans gain work experience through time-limited positions in actual work settings in the community or at VHA medical centers. Per VHA policy, work settings include, but are not limited to, the following: housekeeping, grounds maintenance, and clerical duties involving nonsensitive patient information. The goal of TW is to prepare participants to successfully transition into competitive employment. In contrast, IT is a prevocational work program in which Veterans perform work at VHA medical centers. The primary goal of IT is to provide veterans with severe disabilities with opportunities to develop work skills, though competitive employment is not the goal of this service [11]. Voc Assist provides more general employment assistance in group and individual sessions and does not necessarily follow a particular model of vocational rehabilitation, but may include assessment, guidance, and counseling.

\section{Population-Based Reach of Veterans Health Administration Therapeutic and Employment Services}

VHA provides comprehensive ongoing monitoring of Veterans' utilization of employment services and the immediate outcomes of such services [14]. However, less is known about the extent to which the overall population of VHA users with psychiatric diagnoses accesses VHA employment services. The reach of a program or practice is considered one of five dimensions necessary for assessing the population-based impact of an intervention 
(see Reach Effectiveness Adoption Implementation Maintenance framework [15]). It has been argued that an examination of program reach is particularly important in addressing areas of health disparities because it can identify whether people who most need the program receive it [16]. Considering the low rates of employment among Veterans with psychiatric diagnoses relative to the general population (which perhaps could be called an employment disparity), an investigation that addresses the extent to which VHA employment services reach the population of VHA users with psychiatric diagnoses is an important area of inquiry.

Prior analyses identified the number of Veterans who participated in employment services relative to the total number of VHA users with psychiatric diagnoses in fiscal year (FY) 2009 and found that only 3.5 percent of Veterans with a psychiatric diagnosis received employment services [17-19]. Although it cannot be assumed that all Veterans with psychiatric diagnoses who use the VHA have a need for employment services, a recent independent multimethod evaluation suggested a substantial unmet need for employment services among VHA users with psychiatric diagnoses. Specifically, among a representative sample of Veterans with psychiatric diagnoses who were interviewed between November 2008 and August 2009, 10.5 percent reported needing assistance finding a job in the past year, of whom more than 70 percent reported they did not receive any employment services [20]. Moreover, in a review of medical records of Veterans who had an employment need documented during a new treatment episode during FY2007, only 28 percent were offered employment services [21]. The medical record review did not assess the extent to which employment services were offered to Veterans who expressed employment needs during a visit that was not considered a new treatment episode, but, nonetheless, this suggests unmet employment needs.

Importantly, a thorough evaluation of the populationbased reach of an intervention includes identifying the characteristics of people who receive a given intervention, as compared with those who do not [15]. To date, little work has focused on what demographic or clinical characteristics may be associated with receipt of VHA employment services. However, in terms of self-reported need for employment services, a recent evaluation found that Veterans with bipolar disorder were most likely to report needing help finding a job, whereas Veterans with PTSD were the least likely to report needing such assis- tance [20]. Another factor found to be related to employment outcomes and degree of participation in employment services among Veterans is whether they receive income for a service-connected condition [22]. A recent analysis found that a service-connected disability of 50 percent or greater, in particular, was associated with lower likelihood of employment [23]. Particular levels of service-connected disability status may also be associated with receipt of employment services. In sum, understanding the population-based reach of the TSES program requires an evaluation of what percentage of VHA users with psychiatric diagnoses accesses different employment programs and whether particular clinical and demographic factors are associated with receiving TSES services.

\section{Present Evaluation}

We sought to assess the reach of TSES services in a single year by examining the percentage of VHA users with psychiatric diagnoses who accessed employment services and to identify demographic and clinical characteristics associated with accessing such services. Additionally, among VHA users with psychiatric diagnoses who accessed employment services, we sought to identify demographic and clinical characteristics associated with accessing specific types of employment services (i.e., SE, TW, IT, Voc Assist).

\section{METHODS}

We employed a cross-sectional design to identify VHA users with psychiatric diagnoses who accessed employment services during FY2010. VHA administrative data were used to select a 5 percent random sample of all VHA users who received services during FY2010 $(n=277,159)$. This random sample of VHA service users is maintained by the VHA Serious Mental Illness Treatment Resource and Evaluation Center.

\section{Sample Selection}

To address our research questions, we selected from the random sample only VHA users with a psychiatric diagnosis of schizophrenia (International Classification of Diseases [ICD] code 295.0-295.4, 295.6-295.9), bipolar disorder (ICD 296.0-296.1, 296.4-296.8), depression (ICD 293.83, 296.2, 296.3, 296.90, 296.99, 298.0, 300.4, 301.12, 309.0, 309.1, 311), PTSD (ICD 309.81), or another 
anxiety disorder (ICD 300.00-300.02, 300.09-300.10, $300.20-300.23,300.29)$. To be consistent with a recent evaluation of VHA mental health services, including some employment services [20-21,24], we did not use substance use disorders as primary independent variables. VHA users were considered to have a specific psychiatric diagnosis if they were assigned a diagnosis in the same category during one inpatient visit or two outpatient visits during FY2010. Prior research supports this method of using VHA administrative data to ascertain psychiatric diagnosis [25], particularly when the presence of two of the same diagnoses in administrative data [26] are used to determine diagnosis. Within the random sample, 52,542 of the VHA users (19\%) had at least one of the aforementioned psychiatric diagnoses.

\section{Dependent Variables}

Since we were interested in ascertaining whether a VHA user had accessed any employment service, the primary dependent variable was defined as one or more of any of the following TSES visits during FY2010 per VHA inpatient encounters and outpatient administrative data: SE, TW, IT, and Voc Assist. Employment services visits were dichotomized to indicate any utilization of employment services (yes/no).

For additional analyses, the dependent measure was the type of employment services accessed. Of the VHA users who did have at least one employment services visit, 73.1 percent received only one type of employment service and 21.3 percent received two types of employment services, while a smaller percentage received three $(5.33 \%)$ or four $(0.23 \%)$ types of employment services. VHA users with FY2010 visits in more than one of the four employment services categories were coded into mutually exclusive categories based on the following hierarchy: SE, TW, IT, Voc Assist (represented by administrative data stop code numbers 568, 574, 573, and 575 and/or 535, respectively). The mutually exclusive hierarchy was designed to (1) reflect a continuum of the type of employment service most focused on competitive employment and with the largest evidence base (i.e., SE) [27] through type of employment service that is most sheltered and does not focus on competitive employment (i.e., IT) and (2) capture VHA users who received only Voc Assist and no other employment services. Prior research has used a similar hierarchy to classify type of employment services received [25]. In analyses comparing the type of employment services used, the employ- ment service variable was dummy-coded with TW serving as the reference group, because this is the type of employment service most commonly received [14].

\section{Independent Variables}

Demographic and clinical characteristics were ascertained from VHA administrative data. Primary independent variables were the aforementioned psychiatric diagnoses. Similar to previously used methods [28], VHA users with more than one type of psychiatric diagnosis in FY2010 were coded into mutually exclusive diagnostic categories in the following hierarchy based on severity: schizophrenias, bipolar disorders, PTSD, depressive disorders, and other anxiety disorders. For adjusted analyses, psychiatric diagnosis was dummycoded such that schizophrenia served as the reference group, because it is often considered the most severe of psychiatric diagnoses.

Additional independent variables included demographic factors of age (under $45 \mathrm{yr}, 45-64 \mathrm{yr}, 65 \mathrm{yr}$ and over), race (white, black, other, unknown), ethnicity (non-Hispanic, Hispanic, unknown), sex (male, female), and marital status (married, not married/divorced/ unknown) and the clinical variable of a substance use disorder diagnosis (ICD diagnoses 291, 292, 303.0, 303.9, 304, 305.0, 305.2-305.9 excluding .x3) during FY2010 (yes/no). Homelessness status (yes/no) was ascertained by the receipt of a VHA homelessness service or the presence of a diagnostic indicator of homelessness during FY2010. Service-connected status (50\% or greater, $0 \%-$ $50 \%$, no) was defined by the presence of a disability deemed to be associated with military service. Operation Iraqi Freedom/Operation Enduring Freedom/Operation New Dawn (OIF/OEF/OND) Veteran status (yes/no) was determined using the OIF/OEF/OND roster, a database of Veterans who have been involved in the OIF/OEF/OND mission.

\section{Statistical Analyses}

First, descriptive analyses were conducted to determine the percentage of VHA users with any psychiatric diagnosis that received employment services. Next, bivariate analyses (i.e., chi-square tests) were used to examine the association between demographic and clinical characteristics and the receipt of employment services. Finally, a multivariable logistic regression model and a multivariate multinomial logistic regression model each examined the likelihood of receipt of employment 
services and receipt of specific types of employment services, respectively, based on clinical and demographic factors while controlling for the effect of other variables. These analyses were conducted using SAS 9.3 (SAS Institute Inc; Cary, North Carolina).

In addition to identifying the likelihood of receipt of employment services, we were interested in understanding the predicted probability (i.e., percentage) of VHA users with particular psychiatric diagnoses who received employment services. Thus, in the multivariable models, we employed a "recycled predictions" method that calculates the mean predicted probability of the outcome variable (i.e., receipt of employment services; receipt of specific employment services) based on the coefficients from the fitted regression model, fixing the independent variable of interest (i.e., psychiatric diagnosis) at a specific value while letting the other independent variables vary at their original values for each individual in the sample [29-31]. The process is repeated, fixing the independent variable of interest at the alternate values (i.e., different psychiatric diagnoses). STATA 11 (StataCorp LP; College Station, Texas) was used to compute the recycled predictions models.

\section{RESULTS}

\section{Sample Description}

Among the sample of VHA users with psychiatric diagnoses in FY2010 ( $n=52,542), 90.3$ percent were male, 59.1 percent were middle-aged (between 45 and $64 \mathrm{yr}), 71.9$ percent were Caucasian, and 87.1 percent were non-Hispanic. About half the sample was married (48.3\%). Relatively equal proportions of the sample were not service connected $(40.8 \%)$ or were service connected at 50 percent or greater $(41.1 \%)$, with relatively fewer Veterans being service connected at less than 50 percent (18\%). The most common psychiatric diagnoses were depression (41.4\%) and PTSD (39.7\%). Table 1 contains additional sample characteristics.

\section{Receipt of Employment Services}

Within the sample of VHA users with psychiatric diagnoses, 4.2 percent $(n=2,178)$ received at least one employment service visit in FY2010. Bivariate associations between demographic and clinical characteristics and receipt of any employment services are displayed in Table 1 along with the results of the multivariable logis- tic regression analysis modeling the odds of receipt of employment services. The multivariable analysis indicated that VHA users who were black, had a substance use disorder, or had an indication of homelessness were significantly more likely to receive employment services, while VHA users who were aged 45 and over, were married, had an unknown ethnicity or race, or had a serviceconnected disability of 50 percent or greater were less likely to receive employment services (See Table 1 for odds ratios).

Additionally, as compared with VHA users with schizophrenia, VHA users with PTSD, depression, or another anxiety disorder were less likely to receive employment services. VHA users with bipolar disorder did not significantly differ in their odds of receiving employment services as compared with VHA users with schizophrenia. Accordingly, after adjusting for demographic and other clinical factors, the predicted probability of VHA users with schizophrenia receiving employment services was 5.61 percent and was significantly higher than the predicted probability of VHA users with PTSD (3.97\%), depression (3.96\%), or other anxiety disorders (2.33\%) receiving employment services (all $p<$ 0.001 ). The predicted probability of VHA users with bipolar disorder receiving employment services was 5.63 percent and was not significantly different from that of VHA users with schizophrenia. Additionally, supplemental analyses (not shown) indicated that VHA users with bipolar disorder were more likely than VHA users with PTSD, depression, or other anxiety disorders to receive employment services.

\section{Accessing Specific Types of Employment Services: Supported Employment, Transitional Work, Incentive Therapy, and Vocational Assistance}

Among the sample of VHA users with psychiatric diagnoses who accessed employment services $(n=$ 2,178), 34.9 percent received TW, 30.0 percent received Voc Assist, 27.6 percent received SE, and 7.6 percent received IT. Bivariate associations between clinical and demographic factors and the receipt of a specific type of employment service are displayed in Table 2. Results of the multinomial logistic regression analysis modeling the likelihood of accessing specific types of employment services are displayed in Table 3. VHA users who received SE as compared with TW were less likely to be black, have a history of homelessness, and have a substance use disorder. In terms of psychiatric diagnoses, as compared 
JRRD, Volume 51, Number 3, 2014

Table 1.

Descriptive statistics and bivariate and multivariate associations between patient characteristics and receipt of employment services $(N=52,542)$.

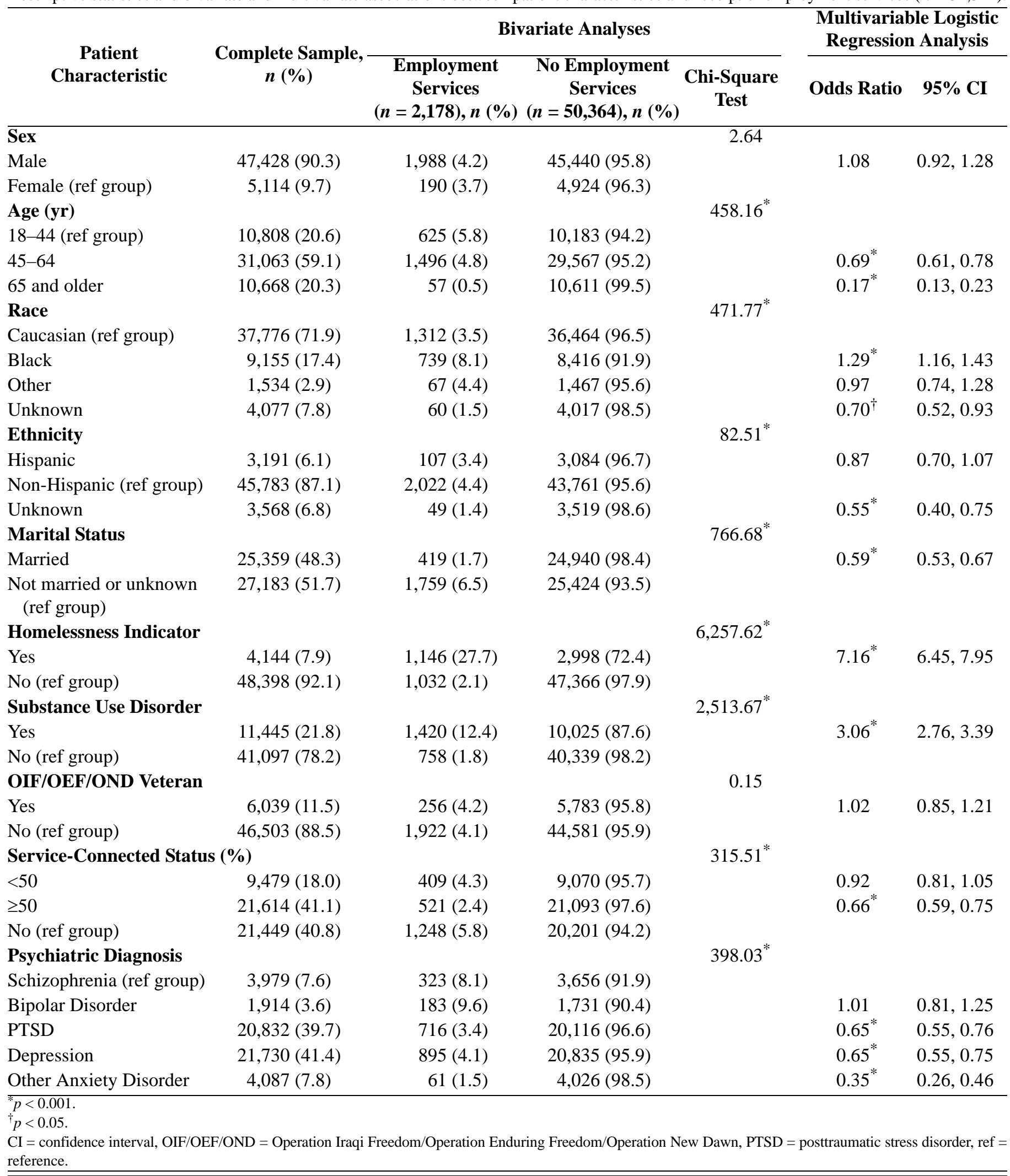


Table 2.

Descriptive statistics and bivariate associations between patient characteristics and receipt of specific types of employment services $(N=2,178)$.

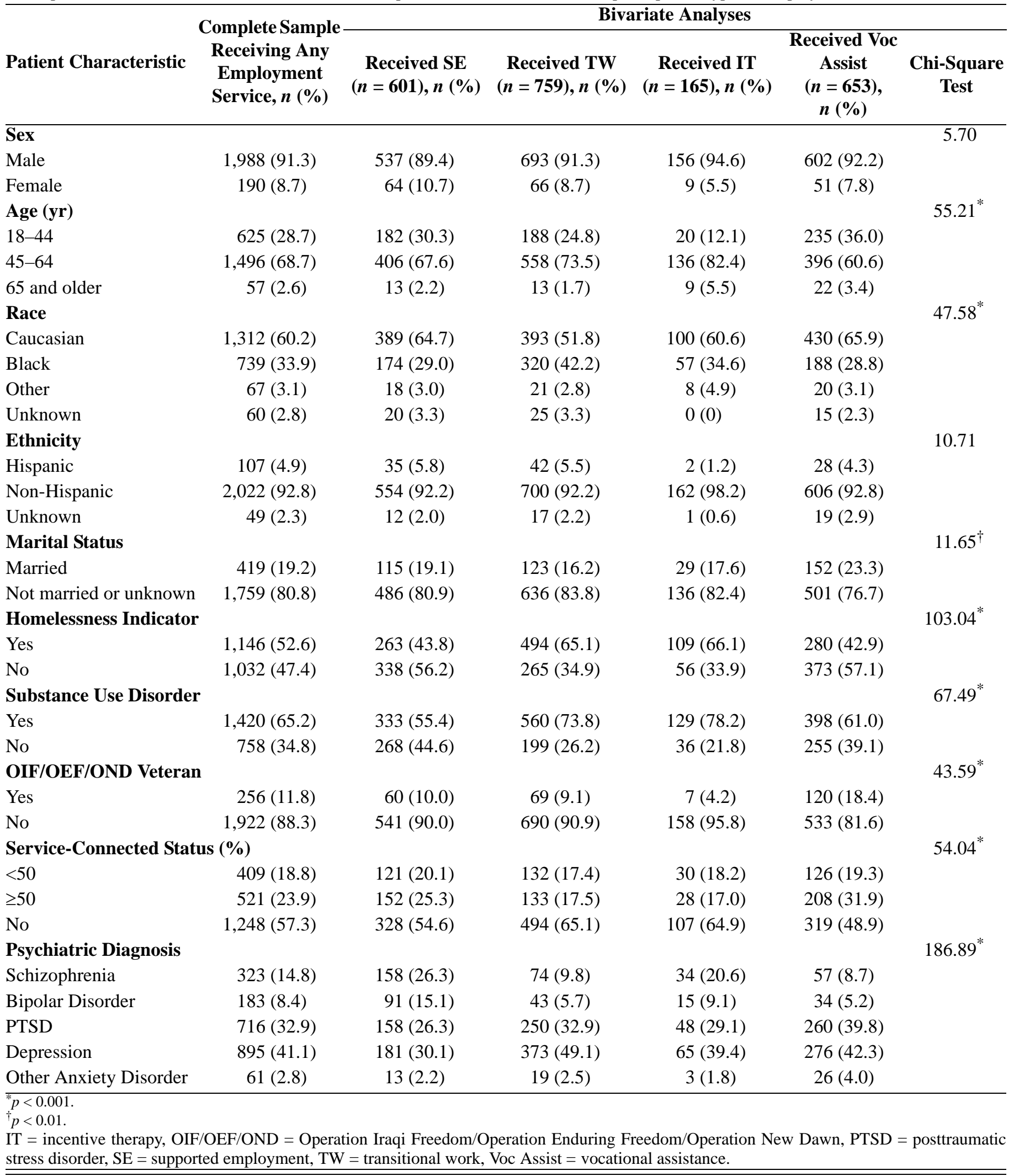


JRRD, Volume 51, Number 3, 2014

Table 3.

Associations between patient characteristics and receipt of specific types of employment services: Multivariable analysis $(N=2,178)$.

\begin{tabular}{|c|c|c|c|c|c|c|}
\hline \multirow{3}{*}{ Patient Characteristic } & \multicolumn{6}{|c|}{ Multinomial Logistic Regression } \\
\hline & \multicolumn{2}{|c|}{ SE (vs TW) } & \multicolumn{2}{|c|}{ IT (vs TW) } & \multicolumn{2}{|c|}{ Voc Assist (vs TW) } \\
\hline & OR & 95\% CI & OR & 95\% CI & OR & $95 \% \mathrm{CI}$ \\
\hline \multicolumn{7}{|l|}{$\overline{\text { Sex }}$} \\
\hline Male & 1.01 & $0.68,1.50$ & 1.36 & $0.65,2.87$ & 1.48 & $0.98,2.22$ \\
\hline Female (ref group) & - & - & - & - & - & - \\
\hline \multicolumn{7}{|l|}{ Age (yr) } \\
\hline 18-44 (ref group) & - & - & - & - & - & - \\
\hline 45-64 & 0.91 & $0.68,1.22$ & $2.49^{*}$ & $1.40,4.45$ & 0.86 & $0.64,1.14$ \\
\hline 65 and older & 0.74 & $0.32,1.73$ & $5.86^{\dagger}$ & $2.08,16.50$ & 1.39 & $0.66,2.95$ \\
\hline \multicolumn{7}{|l|}{ Race } \\
\hline Caucasian (ref group) & - & - & - & - & - & - \\
\hline Black & $0.61^{\dagger}$ & $0.47,0.79$ & $0.58^{*}$ & $0.40,0.84$ & $0.64^{\dagger}$ & $0.50,0.81$ \\
\hline Other & 0.88 & $0.45,1.73$ & 1.66 & $0.70,3.95$ & 0.94 & $0.49,1.81$ \\
\hline Unknown & 0.65 & $0.34,1.26$ & 0.00 & $0.00,99.99$ & $0.39^{*}$ & $0.19,0.78$ \\
\hline \multicolumn{7}{|l|}{ Ethnicity } \\
\hline Hispanic & 0.86 & $0.52,1.41$ & $0.19^{\ddagger}$ & $0.05,0.80$ & 0.61 & $0.37,1.02$ \\
\hline Non-Hispanic (ref group) & - & - & - & - & - & - \\
\hline Unknown & 0.83 & $0.37,1.88$ & 0.32 & $0.04,2.49$ & 1.68 & $0.82,3.45$ \\
\hline \multicolumn{7}{|l|}{ Marital Status } \\
\hline Married & 0.97 & $0.71,1.32$ & 1.31 & $0.81,2.11$ & 1.00 & $0.75,1.33$ \\
\hline Not married or unknown (ref group) & - & - & - & - & - & - \\
\hline \multicolumn{7}{|l|}{ Homelessness Indicator } \\
\hline Yes & $0.60^{\dagger}$ & $0.46,0.77$ & 1.08 & $0.72,1.62$ & $0.52^{\dagger}$ & $0.41,0.66$ \\
\hline No (ref group) & - & - & - & - & - & - \\
\hline \multicolumn{7}{|l|}{ Substance Use Disorder } \\
\hline Yes & $0.57^{\dagger}$ & $0.44,0.74$ & 1.29 & $0.82,2.01$ & 0.78 & $0.60,1.01$ \\
\hline No (ref group) & - & - & - & - & - & - \\
\hline \multicolumn{7}{|l|}{ OIF/OEF/OND Veteran Status } \\
\hline Yes & 0.87 & $0.56,1.35$ & 0.88 & $0.35,2.24$ & 1.33 & $0.89,1.97$ \\
\hline No (ref group) & - & - & - & - & - & - \\
\hline \multicolumn{7}{|l|}{ Service-Connected Status (\%) } \\
\hline$<50$ & 1.29 & $0.95,1.76$ & 1.24 & $0.78,1.98$ & $1.35^{\ddagger}$ & $1.00,1.82$ \\
\hline$\geq 50$ & 1.14 & $0.84,1.56$ & 1.07 & $0.65,1.78$ & $1.80^{\dagger}$ & $1.34,2.41$ \\
\hline No (ref group) & - & - & - & - & - & - \\
\hline \multicolumn{7}{|l|}{ Psychiatric Diagnosis } \\
\hline Schizophrenia (ref group) & - & - & - & - & - & - \\
\hline Bipolar Disorder & 0.97 & $0.61,1.56$ & 0.69 & $0.33,1.44$ & 1.04 & $0.58,1.86$ \\
\hline PTSD & $0.30^{\dagger}$ & $0.21,0.43$ & $0.41^{\dagger}$ & $0.24,0.69$ & 1.28 & $0.85,1.92$ \\
\hline Depression & $0.25^{\dagger}$ & $0.18,0.35$ & $0.35^{\dagger}$ & $0.21,0.58$ & 1.22 & $0.82,1.82$ \\
\hline Other Anxiety Disorder & $0.32^{*}$ & $0.15,0.70$ & 0.35 & $0.09,1.27$ & 2.01 & $0.99,4.09$ \\
\hline \multicolumn{7}{|c|}{$\begin{array}{l}{ }^{7} p<0.01 . \\
{ }^{\dagger} p<0.001 . \\
{ }^{{ }^{\dagger}} p<0.05 . \\
\text { CI = confidence interval, IT = incentive therapy, OR = odds ratio, OIF/OEF/OND = Operation Iraqi Freedom, Operation Enduring Freedom, Operation New Dawn, } \\
\text { PTSD = posttraumatic stress disorder, ref = reference, SE = supported employment, TW = transitional work, Voc Assist = vocational assistance. }\end{array}$} \\
\hline
\end{tabular}


with VHA users with schizophrenia, VHA users with PTSD, depression, and other anxiety disorders were less likely to receive SE than TW.

VHA users who received IT as compared with TW were more likely to be $45 \mathrm{yr}$ or older than to be $18-44 \mathrm{yr}$ old. VHA users who received IT as compared with TW were also less likely to be black or of Hispanic ethnicity. Finally, VHA users with psychiatric diagnoses of PTSD or depression as compared with VHA users with schizophrenia were less likely to receive IT than TW.

VHA users who received Voc Assist as compared with TW were less likely to be black or have an unknown race and less likely to have an indication of homelessness. Conversely, VHA users who were service connected (at any percentage) were more likely to receive Voc Assist compared with TW. Compared with VHA users with schizophrenia, VHA users with bipolar disorder, PTSD, and depression were no more or less likely to receive Voc Assist compared with TW.

Table 4 illustrates the predicted probabilities for receiving specific types of employment services among VHA users with psychiatric diagnoses who received any employment service $(n=2,178)$ and whether these predicted probabilities differed based on psychiatric diagnosis, after adjusting for clinical and demographic factors. Regarding receipt of SE, the predicted probability of VHA users with schizophrenia receiving SE was 47.78 percent and was significantly higher than the predicted probability of those with PTSD (22.77\%), depression $(20.13 \%)$, or other anxiety disorders (20.37\%) receiving $\mathrm{SE}$ (all $p<0.001$ ). The predicted probability of VHA users with bipolar disorder receiving SE was 48.41 percent, which was not significantly different from that of VHA users with schizophrenia, and supplemental analyses (not shown) indicated VHA users with bipolar disorder were also more likely to receive SE than those with PTSD, depression, or other anxiety disorders. Furthermore, VHA users with PTSD or depression had significantly higher predicted probabilities $(36.73 \%$ and $39.17 \%$, respectively, $p<0.001$ ) of receiving TW than VHA users with schizophrenia (23.87\%). The predicted probabilities of VHA users with PTSD $(7.26 \%, p=0.05)$ or depression $(6.62 \%, p<0.05)$ receiving IT were significantly lower than that of VHA users with schizophrenia (11.45\%). The predicted probabilities of receiving Voc Assist services were significantly higher among VHA users with PTSD (33.24\%), depression (34.07\%), and other anxiety disorders (43.11\%) compared with VHA users with schizophrenia $(16.91 \%$; all $p<0.001)$.

\section{DISCUSSION}

This study sought to describe the reach of employment services to the population of VHA users with psychiatric diagnoses. Overall, findings suggest that only a small percentage of VHA users with psychiatric diagnoses access employment services in a given year-a finding that is consistent with a prior report [17-19]. In this representative sample, VHA users with psychiatric diagnoses of schizophrenia had higher odds of accessing any employment services relative to VHA users with other psychiatric diagnoses, including PTSD, depression, and other anxiety disorders, but did not differ in their odds of accessing employment services as compared with VHA users with bipolar disorder. Despite differences in accessing employment services based on psychiatric diagnosis, it is important to note that the percentage of VHA users who accessed employment services in $1 \mathrm{yr}$ is relatively low across persons in all psychiatric diagnostic categories

Table 4.

Recycled predictions: Predicted probabilities of receipt of specific types of employment services.

\begin{tabular}{|c|c|c|c|c|}
\hline Psychiatric Diagnosis & \multicolumn{4}{|c|}{ Margin } \\
\hline Bipolar Disorder & $48.41^{\mathrm{a}}$ & $24.98^{\mathrm{a}}$ & $8.36^{\mathrm{a}}$ & $18.25^{\mathrm{a}}$ \\
\hline Depression & $20.13^{b}$ & $39.17^{\mathrm{C}}$ & $6.62^{b}$ & $34.07^{\mathrm{C}}$ \\
\hline Other Anxiety Disorder & $20.37^{b}$ & $31.27^{\mathrm{a}}$ & $5.25^{\mathrm{a}}$ & $43.11^{\mathrm{C}}$ \\
\hline 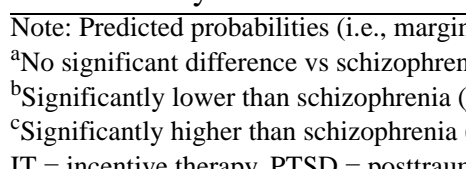 & demogi & ariables & 3. & (1) \\
\hline
\end{tabular}


(range unadjusted: 1.5\% [anxiety disorders other than PTSD] to $9.6 \%$ [bipolar disorder]; range adjusted for demographic and clinical variables: $2.3 \%$ [anxiety disorders other than PTSD] to 5.6\% [schizophrenia and bipolar disorder]). Although VHA policy suggests that the scope of the TSES program is to provide employment services to all Veterans with psychiatric conditions who are interested in developing work-related skills [11], the present study findings suggest that the reach of employment services to the population of Veterans with psychiatric diagnoses in VHA is limited.

Notably, among VHA users with psychiatric diagnoses, those who were black, had a diagnosis of a substance use disorder, or had an indication of homelessness were more likely to receive employment services. Given that people who are black [32] or have substance use disorders [33] generally face higher rates of unemployment, it is encouraging that VHA users with psychiatric diagnoses and these sociodemographic characteristics were more likely to access employment services. Yet, while individuals with these sociodemographic characteristics were more likely to receive employment services, they were less likely to receive SE as compared with TW. This is of particular concern because SE is an evidence-based practice for obtaining employment and TW is not. Reasons for this disparity in receiving evidence-based employment services require further investigation before they can be effectively addressed. It is possible that there may be limited availability of SE in VHA facilities in particular geographic regions that serve higher proportions of Veterans who are black, homeless, or have a substance use disorder. A recent independent evaluation indicated some degree of variability in the extent to which Veterans received SE across VHA regions [24]. Alternatively, biases in clinical judgment with regard to which Veterans might benefit from evidence-based services could be investigated as a potential barrier to accessing SE. Whether the size and availability of existing employment service programs across the VHA or mental health service providers' expectations [34-35] are associated with the reach of employment services in general or evidence-based employment services specifically are important areas of future study.

Our finding that VHA users with a service-connected disability of 50 percent or higher were less likely to access employment services is consistent with prior research [22]. Notably, our data suggest that having a service-connected disability of less than 50 percent was not associated with a lower likelihood of receiving employment services. This is consistent with a recent finding that service-connected disabilities of 50 percent or higher (but not necessarily lower levels) were associated with unemployment and not looking for employment [23]. Regulations associated with loss of Social Security Administration medical and financial benefits due to employment may act as a disincentive to return to competitive employment [36-37], though perhaps only at higher levels of service-connected disability [35]. Although Department of Veterans Affairs (VA) benefits are not reduced due to income earned through VHA employment services, whether the perception of a loss of VA benefits acts as a disincentive to even seeking VHA employment services is an important research and policy consideration. Educating clinicians and patients about these issues could help to increase rates of participation in VHA employment services.

Present study analyses also indicated that among VHA users who accessed employment services, those with schizophrenia or bipolar disorder were more likely to receive SE, while those with PTSD or depression were more likely to receive TW or Voc Assist. The majority of research supporting the effectiveness of SE was conducted in samples of people with psychotic or mood disorders [13] and VHA guidelines suggest that a minimum of 75 percent of Veterans enrolled in SE should be individuals with psychosis [25]; thus, it is not surprising that VHA users with schizophrenia or bipolar disorder were more likely to access SE. Moreover, it is possible that VHA users with less severe mental health conditions require less intensive employment services. Little is known, however, regarding the type(s) of employment services that are preferred or most effective among Veterans with diagnoses of depression, PTSD, or other anxiety disorders. The single randomized controlled trial of TW among VHA patients found it did not improve competitive employment among Veterans with nonpsychotic psychiatric diagnoses and comorbid substance use disorders, though Veterans who received TW were more likely to engage in paid activity and work more hours through the program than those who received standard job placement [38]. Additionally, since a variety of services could be encompassed by Voc Assist, it is unclear whether the employment services and strategies Veterans receive are effective.

Given TW and/or Voc Assist services are most likely to reach VHA users with PTSD, depression, and other 
anxiety disorders, further study is needed to identify type(s) of employment services that will be most effective for these populations. A recent study of OIF/OEF Veterans referred for mental health assessment found that 59 percent were employed and that among those employed, psychiatric diagnoses of major depressive disorder, other anxiety disorders, and PTSD were each associated with impaired work performance [39]. For Veterans with certain psychiatric diagnoses, it is possible that employment services that include improving work performance in existing jobs may be as relevant as employment services that focus on obtaining employment. Importantly, a recent randomized controlled trial found SE efficacious in improving employment outcomes among unemployed Veterans with PTSD [40]. Moreover, SE services appear to be effective for OIF/ OEF Veterans with PTSD (see Twamley et al. [25] for a discussion). Hence, the availability of SE services for unemployed Veterans with PTSD may be critical for improving employment outcomes.

\section{LIMITATIONS}

Reliance on administrative data limited the present analyses in that we were unable to ascertain VHA users' current employment status and their desire for employment or employment services [17] and their utilization of non-VHA employment services (including employment services or referrals provided through the Veterans Benefits Administration), which, along with other individuallevel factors, would likely influence whether or not a Veteran attempted to access VHA employment services. Although prior research suggests psychiatric diagnosis can be validly ascertained from administrative data [26], it is possible that our use of administrative data to identify diagnosis resulted in an underdetection of psychiatric conditions. Additionally, we did not assess receipt of employment services over time, but focused on the reach of services in a single year. Finally, since present analyses examined reach of employment services, rather than the degree of Veterans' participation in, or the effectiveness, efficacy, or fidelity of such services, we selected a liberal operational definition of accessing employment services (i.e., receiving one visit of employment services). Of course, it is unlikely that one employment service visit would be sufficient in terms of addressing the employment needs of Veterans with psychiatric diagno- ses. Given the low rates of accessing even one employment service-related visit, the number of patients who received potentially effective services was even smaller. Notably, in supplemental analyses (not shown) we used another standard definition of meaningful participation in employment services [14] and found that only 1.9 percent of Veterans with psychiatric diagnoses received four or more visits of one specific type of employment service during FY2010.

Similarly, the mutually exclusive hierarchy we used to define receipt of specific types of employment services was constructed to examine the relative percentage of VHA users who accessed only one visit of a particular type of service, beginning with SE. This method likely overestimates the percentage of Veterans who received multiple visits of SE, while underestimating the percentage of Veterans who received multiple visits of TW, IT, or Voc Assist (see Resnick et al. [14] for an evaluation of VHA employment services that considers number of visits to SE and TW). Despite this, the present analyses offer an estimate of VHA users with psychiatric disabilities who did gain access to at least one visit of particular types of employment services. Future investigations regarding the reach of VHA employment services should examine with greater detail the various types of employment services received by Veterans with psychiatric diagnoses, consider the number of Veterans who receive effective employment services, and identify what factors are associated with receiving effective services.

\section{CONCLUSIONS}

The present analyses extend the current literature in that they provide a population-based examination of the reach of VHA employment services for VHA users with psychiatric diagnoses. Only 4.2 percent of VHA users with psychiatric diagnoses accessed employment services during FY2010, suggesting potentially substantial unmet employment-related needs for VHA patients with a wide range of psychiatric conditions. Additionally, the majority of Veterans who receive employment services do not receive evidence-based services. Future investigations are needed to identify factors at multiple ecological levels of analysis (e.g., regional, facility, provider, Veteran) associated with accessing employment services for Veterans with psychiatric diagnoses. Particular attention should be paid to the availability of evidence-based 
employment services, namely supported employment, across VHA facilities.

Given a protracted recession, a weak economy, and prior research illustrating high unemployment rates among Veterans with psychiatric diagnoses, this work highlights that as of FY2010, existing efforts to increase supply of and access to employment-related services for VHA patients with psychiatric diagnoses may have been insufficient to meet the demand for support. Notably these findings also highlight the importance of more recent VHA employment programs implemented after FY2010, including the Homeless Veterans Supported Employment Program and the Vocational Rehabilitation and Employment Vet Success Program, which target employment assistance to Veterans with histories of or at risk for homelessness and Veterans with service-connected disabilities who were recently separated from the military [41]. Although these programs do not specifically target Veterans with psychiatric diagnoses, certainly some Veterans with psychiatric diagnoses may benefit from them.

Overall, the present study findings indicate that the reach of employment services to Veterans with psychiatric diagnoses is quite limited and suggest the VHA should consider expanding the availability of employment services, particularly evidence-based employment services (i.e., SE). Such an expansion would represent a commitment to treatments that explicitly focus on improving the functioning of Veterans with psychiatric conditions and would be consistent with the VHA's efforts to adopt recovery-oriented mental health services [42].

\section{ACKNOWLEDGMENTS}

\author{
Author Contributions: \\ Conceptualized research question: K. M. Abraham, K. Zivin. \\ Contributed to study design: K. M. Abraham, K. Zivin, D. Ganoczy, \\ S. G. Resnick. \\ Data analysis: D. Ganoczy, M. Yosef. \\ Data interpretation: D. Ganoczy, S. G. Resnick. \\ Drafted manuscript: K. M. Abraham, K. Zivin. \\ Edited manuscript: D. Ganoczy. \\ Approved final manuscript: K. M. Abraham, K. Zivin, D. Ganoczy, \\ S. G. Resnick, M. Yosef.
}

Financial Disclosures: The authors have declared that no competing interests exist.

Funding/Support: Although the research presented here was not directly funded, Dr. Abraham's work on this was supported, in part, by the VA Office of Academic Affiliations, Advanced Fellowship Program in Mental Illness Research and Treatment. Dr. Zivin's work was supported by the VA, VHA, Health Services Research and Development Service (grants IIR 10-176-3 and CDA 2 07-206-1).

Additional Contributions: The authors thank Erin Miller for her assistance in preparing this manuscript.

Institutional Review: Analyses were approved by VA Ann Arbor Institutional Review Board.

Disclaimer: The views expressed in this manuscript are those of the authors and do not necessarily represent the views of the VA.

\section{REFERENCES}

1. Jans L, Stoddard S, Kraus L. Chartbook on mental health and disability in the United States. Washington (DC): Department of Education, National Institute on Disability and Rehabilitation Research; 2004.

2. Sturm R, Gresenz CR, Pacula RL, Wells KB. Datapoints: Labor force participation by persons with mental illness. Psychiatr Serv. 1999;50(11):1407. [PMID:10543847]

3. Macias C, DeCarlo LT, Wang Q, Frey J, Barreira P. Work interest as a predictor of competitive employment: Policy implications for psychiatric rehabilitation. Adm Policy Ment Health. 2001;28(4):279-97. [PMID:11577655] http://dx.doi.org/10.1023/A:1011185513720

4. Shippee ND, Shah ND, Williams MD, Moriarty JP, Frye MA, Ziegenfuss JY. Differences in demographic composition and in work, social, and functional limitations among the populations with unipolar depression and bipolar disorder: Results from a nationally representative sample. Health Qual Life Outcomes. 2011;9(90):90.

[PMID:21995725]

http://dx.doi.org/10.1186/1477-7525-9-90

5. Kessler RC, Frank RG. The impact of psychiatric disorders on work loss days. Psychol Med. 1997;27(4):861-73. [PMID:9234464] http://dx.doi.org/10.1017/S0033291797004807

6. Zivin K, Bohnert AS, Mezuk B, Ilgen MA, Welsh D, Ratliff S, Miller EM, Valenstein M, Kilbourne AM. Employment status of patients in the VA health system: Implications for mental health services. Psychiatr Serv. 2011;62(1):35-38. [PMID:21209297] http://dx.doi.org/10.1176/appi.ps.62.1.35

7. Goodwin AM. Kennedy 1 A. The psychosocial benefits of work for people with severe and enduring mental health problems. Community Work Fam. 2005;8(1):23-35. http://dx.doi.org/10.1080/1366880052000323986

8. Dunn EC, Wewiorski NJ, Rogers ES. The meaning and importance of employment to people in recovery from serious mental illness: Results of a qualitative study. Psychiatr Rehabil J. 2008;32(1):59-62. [PMID:18614451] http://dx.doi.org/10.2975/32.1.2008.59.62

9. Vick B, Jones K, Mitra S. Poverty and severe psychiatric disorder in the U.S.: Evidence from the Medical Expenditure 
Panel Survey. J Ment Health Policy Econ. 2012;15(2):83-96. [PMID:22813941]

10. Peffer PA. Money: A rehabilitation incentive for mental patients. Am J Psychiatry. 1953;110(2):84-92. [PMID:13065520]

11. Department of Veterans Affairs. Therapeutic and supported employment services program. VHA Handbook 1163.02. Washington (DC): Department of Veterans Affairs; 2011.

12. Twamley EW, Jeste DV, Lehman AF. Vocational rehabilitation in schizophrenia and other psychotic disorders: A literature review and meta-analysis of randomized controlled trials. J Nerv Ment Dis. 2003;191(8):515-23.

[PMID:12972854]

http://dx.doi.org/10.1097/01.nmd.0000082213.42509.69

13. Campbell K, Bond GR, Drake RE. Who benefits from supported employment: A meta-analytic study. Schizophr Bull. 2011;37(2):370-80. [PMID:19661196]

http://dx.doi.org/10.1093/schbul/sbp066

14. Resnick SG, Kaczynski R, Sieffert D, Tyler KA, Showalter D, Gray S, Cahill J, Ackles A, Hoff R. Sixteenth progress report on the compensated work therapy (CWT) program: Fiscal year 2012. Report to the U.S. Congress. West Haven (CT): Northeast Program Evaluation Center; 2013.

15. Glasgow RE, Vogt TM, Boles SM. Evaluating the public health impact of health promotion interventions: The REAIM framework. Am J Public Health. 1999;89(9):1322-27. [PMID:10474547] http://dx.doi.org/10.2105/AJPH.89.9.1322

16. Glasgow RE, Eckstein ET, Elzarrad MK. Implementation science perspectives and opportunities for HIV/AIDS research: Integrating science, practice, and policy. J Acquir Immune Defic Syndr. 2013;63(Suppl 1):S26-31.

[PMID:23673882] http://dx.doi.org/10.1097/QAI.0b013e3182920286

17. Drebing CE, Mueller L, Van Ormer EA, Duffy P, LePage J, Rosenheck R, Drake R, Rose GS, King K, Penk W. Pathways to vocational services: Factors affecting entry by veterans enrolled in Veterans Health Administration mental health services. Psychol Serv. 2012;9(1):49-63.

[PMID:22449087]

http://dx.doi.org/10.1037/a0026662

18. Resnick SG, Kaczynski R, Sieffert D, Baldino R, Showalter D, Gray S. Twelfth progress report of the compensated work therapy (CWT) program: Fiscal year 2008. West Haven (CT): Northeast Program Evaluation Center; 2009.

19. Greenberg G, Rosenheck R. National Mental Health Program Performance Monitoring System: Fiscal year 2008 report. West Haven (CT): Department of Veterans Affairs Northeast Program Evaluation Center; 2009.

20. Hepner KA, Paddock SM, Watkins KE, Solomon J, Burkhart Q, Smith B, Pincus HA. Program evaluation of VHA mental health services: Client survey report (contract GS
10 F-0261K). Alexandria (VA): Altarum Institute and RAND-University of Pittsburgh Health Institute; 2010.

21. Farmer C, Watkins K, Smith B, Paddock S, Woodroffe A, Solomon J, Sorbero M, Hepner K, Forrest L, Shugarman L, Call C, Pincus HA. Program evaluation of VHA mental health services: Medical record review report (contract GS $10 \mathrm{~F}-0261 \mathrm{~K}$ ). Alexandria (VA): Altarum Institute and RAND-University of Pittsburgh Health Institute; 2010.

22. Drew D, Drebing CE, Van Ormer A, Losardo M, Krebs C, Penk W, Rosenheck RA. Effects of disability compensation on participation in and outcomes of vocational rehabilitation. Psychiatr Serv. 2001;52(11):1479-84.

[PMID:11684743]

http://dx.doi.org/10.1176/appi.ps.52.11.1479

23. Tsai J, Rosenheck RA. Examination of Veterans Affairs disability compensation as a disincentive for employment in a population-based sample of veterans under age 65. J Occup Rehabil. 2013;23(4):504-12.

24. Altarum Institute. Program evaluation of VHA mental health services: Administrative data report (contract GS 10F-0261K). Alexandria (VA): Altarum Institute; 2010.

25. Twamley EW, Baker DG, Norman SB, Pittman JO, Lohr JB, Resnick SG. Veterans Health Administration vocational services for Operation Iraqi Freedom/Operation Enduring Freedom Veterans with mental health conditions. J Rehabil Res Dev. 2013;50(5):663-70. [PMID:24013914] http://dx.doi.org/10.1682/JRRD.2012.08.0137

26. Frayne SM, Miller DR, Sharkansky EJ, Jackson VW, Wang F, Halanych JH, Berlowitz DR, Kader B, Rosen CS, Keane TM. Using administrative data to identify mental illness: What approach is best? Am J Med Qual. 2010;25(1):42-50. [PMID:19855046] http://dx.doi.org/10.1177/1062860609346347

27. Dixon LB, Dickerson F, Bellack AS, Bennett M, Dickinson D, Goldberg RW, Lehman A, Tenhula WN, Calmes C, Pasillas RM, Peer J, Kreyenbuhl J; Schizophrenia Patient Outcomes Research Team (PORT). The 2009 schizophrenia PORT psychosocial treatment recommendations and summary statements. Schizophr Bull. 2010;36(1):48-70. [PMID:19955389] http://dx.doi.org/10.1093/schbul/sbp115

28. Kilbourne AM, Morden NE, Austin K, Ilgen M, McCarthy JF, Dalack G, Blow FC. Excess heart-disease-related mortality in a national study of patients with mental disorders: Identifying modifiable risk factors. Gen Hosp Psychiatry. 2009;31(6):555-63. [PMID:19892214] http://dx.doi.org/10.1016/j.genhosppsych.2009.07.008

29. Zivin K, Campbell DG, Lanto AB, Chaney EF, Bolkan C, Bonner LM, Miller EM, Valenstein M, Waltz TJ, Rubenstein LV. Relationships between mood and employment over time among depressed VA primary care patients. Gen 
Hosp Psychiatry. 2012;34(5):468-77. [PMID:22771108] http://dx.doi.org/10.1016/j.genhosppsych.2012.05.008

30. Graubard BI, Korn EL. Predictive margins with survey data. Biometrics. 1999;55(2):652-59. [PMID:11318229] http://dx.doi.org/10.1111/j.0006-341X.1999.00652.x

31. Kleinman LC, Norton EC. What's the risk? A simple approach for estimating adjusted risk measures from nonlinear models including logistic regression. Health Serv Res. 2009;44(1):288-302. [PMID:18793213] http://dx.doi.org/10.1111/j.1475-6773.2008.00900.x

32. Bureau of Labor Statistics. Unemployment rate demographics, September 2010 [Internet]. Washington (DC): Bureau of Labor Statistics. 2010 Sep [cited 2014 Apr 24]. Available from: http://www.bls.gov/opub/ted/2010/ted_20101013.htm

33. Henkel D. Unemployment and substance use: A review of the literature (1990-2010). Curr Drug Abuse Rev. 2011; 4(1):4-27. [PMID:21466502] http://dx.doi.org/10.2174/1874473711104010004

34. Casper ES, Carloni C. Assessing the underutilization of supported employment services. Psychiatr Rehabil J. 2007;30(3):182-88. [PMID:17269268] http://dx.doi.org/10.2975/30.3.2007.182.188

35. Abraham KM, Stein CH. Case managers' expectations about employment for people with psychiatric disabilities. Psychiatr Rehabil J. 2009;33(1):9-17. [PMID:19592374] http://dx.doi.org/10.2975/33.1.2009.9.17

36. MacDonald-Wilson KL, Rogers ES, Ellison ML, Lyass A. A study of the social security work incentives and their relation to perceived barriers to work among persons with psychiatric disability. Rehabil Psychol. 2003;48(4):301-9. http://dx.doi.org/10.1037/0090-5550.48.4.301

37. O’Day B, Killeen M. Does U.S. Federal policy support employment and recovery for people with psychiatric disabilities? Behav Sci Law. 2002;20(6):559-83.

[PMID:12465128] http://dx.doi.org/10.1002/bsl.514

38. Penk W, Drebing CE, Rosenheck RA, Krebs C, Van Ormer A, Mueller L. Veterans Health Administration transitional work experience vs. job placement in veterans with comorbid substance use and non-psychotic psychiatric disorders. Psychiatr Rehabil J. 2010;33(4):297-307.
[PMID:20374988]

http://dx.doi.org/10.2975/33.4.2010.297.307

39. Adler DA, Possemato K, Mavandadi S, Lerner D, Chang H, Klaus J, Tew JD, Barrett D, Ingram E, Oslin DW. Psychiatric status and work performance of veterans of Operations Enduring Freedom and Iraqi Freedom. Psychiatr Serv. 2011;62(1):39-46. [PMID:21209298]

http://dx.doi.org/10.1176/appi.ps.62.1.39

40. Davis LL, Leon AC, Toscano R, Drebing CE, Ward LC, Parker PE, Kashner TM, Drake RE. A randomized controlled trial of supported employment among veterans with posttraumatic stress disorder. Psychiatr Serv. 2012;63(5): 464-70. [PMID:22307881] http://dx.doi.org/10.1176/appi.ps.201100340

41. Department of Veterans Affairs. Homeless veterans: Employment programs [Internet]. Washington (DC): Department of Veterans Affairs; 2013 [updated 2012 Nov 27; cited 2014 Apr 25]. Available from: http://www.va.gov/ HOMELESS/employment programs.asp

42. Goldberg RW, Resnick SG. US Department of Veterans Affairs (VA) efforts to promote psychosocial rehabilitation and recovery. Psychiatr Rehabil J. 2010;33(4):255-58.

[PMID:20374981]

http://dx.doi.org/10.2975/33.4.2010.255.258

Submitted for publication May 8, 2013. Accepted in revised form October 21, 2013.

This article and any supplementary material should be cited as follows:

Abraham KM, Ganoczy D, Yosef M, Resnick SG, Zivin $\mathrm{K}$. Receipt of employment services among Veterans Health Administration users with psychiatric diagnoses. J Rehabil Res Dev. 2014;51(3):401-14.

http://dx.doi.org/10.1682/JRRD.2013.05.0114

ResearcherID/ORCID: Sandra G. Resnick, PhD: F-38832014

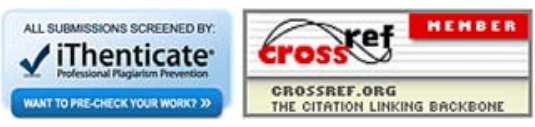

